\title{
SOSIAL MEDIA DAN PERUBAHAN INDEKS PRESTASI MAHASISWA
}

\author{
Risnah dan Ahmad Sayuti \\ Fakultas Ilmu Kesehatan UIN Alauddin Makassar \\ Jl. Sultan Alauddin No. 36 Samata, Gowa, SULSEL \\ E-mail: risnah_ina@yahoo.com
}

\begin{abstract}
Abstrak:
Tujuan dari penelitian ini adalah mengetahui jumlah mahasiswa semester II, IV, dan VI Jurusan Keperawatan yang menggunakan internet secara aktif dan karakteristiknya, membandingkan hasil belajar mahasiswa semester II-III, IV-V, dan VI-VII Jurusan Keperawatan, dan mengetahui pengaruh sosial media (facebook dan twitter) terhadap perubahan indeks prestasi mahasiswa, dengan jumlah responden sebanyak 150 orang. Penelitian ini adalah deskriptif dengan desain penelitian kausal. Pengumpulan data dengan menggunakan instrumen berupa kuesioner, dengan jumlah responden sebanyak 150 orang. Adapun hasil penelitian menunjukkan bahwa indeks prestasi mahasiswa dengan penggunaan sosial media umumnya responden menyatakan sosial media tidak mempengaruhi indeks prestasi. Dari hasil analisis uji statistik diperoleh terdapat pengaruh antara sosial media (facebook dan twitter) dengan indeks prestasi. Dengan begitu, penggunaan sosial media harus digunakan sebagaimana mestinya, agar mahasiswa/i yang aktif pengunaan sosial media tidak mempengaruhi indeks prestasinya.
\end{abstract}

\begin{abstract}
:
The aim of this study was to determine the number of students of the second semester, IV, and VI Department of Nursing who use the Internet actively by comparing student achievement of the second, the third, the fourth, the fifth, the sixth and the seventh semester of Nursing Department, and to determine the effect of social media (facebook and twitter) on the students' grade point average with 150 respondents as sample. This study was a descriptive causal research design. Instrument used to collect data was questionnaires. The research results showed that the respondents said that social media generally did not affect their Grade point average. However, from the analysis of statistical tests, it was obtained there was influence of social media (facebook and twitter) on the students GPA. Based on this finding, therefore, the use of social media should be used appropriately, so that the students who are active using social media will not affect their GPA.
\end{abstract}

Kata kunci:

Sosial, media, indeks prestasi

BERKEMBANGNYA ilmu pengetahuan dan teknologi di dunia, khususnya sosial media muncul atas dasar ide untuk menghubungkan orang-orang dari seluruh belahan dunia. Kehadiran jejaring sosial diawali dengan munculnya sixdegrees.com pada tahun 1997 sebagai situs jejaring sosial pertama di dunia. Tahun 1999 dan 2000 muncul situs jejaring sosial bernama lunarstorm, live journal, dan cyword dengan sistem informasi searah. 
Pada tahun 2006 kehadiran facebook menggeser posisi jejaring sosial pada saat itu. Facebook yang telah diluncurkan pada tahun 2004 sampai saat ini telah memiliki 750 juta pengguna. Pada tahun 2009, muncul jejaring sosial twitter yang saat ini juga merupakan salah satu jejaring sosial populer. Pengguna twitter (tweep) dibatasi dalam berkicau (tweet) maksimal 140 karakter. Namun, justru pembatasan ini membuat twitter menjadi jejaring sosial micro blogging populer. Karena terbatas, jadi orang hanya menuliskan kata-kata yang penting saja dan tidak lebay seperti di facebook yang telah memiliki 750 juta pengguna. ${ }^{1}$

Indonesia yang merupakan negara berkembang juga mempunyai minat yang cukup tinggi terhadap perkembangan teknologi lebih khususnya ketertarikan yang cukup tinggi terhadap beberapa situs jejaring sosial, seperti yang banyak di informasikan di berbagai media mengenai tingginya pengguna situs jejaring sosial di indonesia yang juga terbukti dengan banyaknya iklan perangkat bergerak yang menyediakan layanan untuk terkoneksi langsung ke situs jejaring sosial. ${ }^{2}$ Tujuan dari penelitian ini adalah mengetahui jumlah mahasiswa semester II, IV, dan VI Jurusan Keperawatan yang menggunakan internet secara aktif dan karakteristiknya, membandingkan hasil belajar mahasiswa semester II-III, IV-V, dan VI-VII Jurusan Keperawatan, dan mengetahui pengaruh sosial media (facebook dan twitter) terhadap perubahan indeks prestasi mahasiswa, dengan jumlah responden sebanyak 150 orang.

\section{TINJAUAN TEORETIS}

\section{Indeks Prestasi}

\section{Prestasi Belajar}

Belajar merupakan aktivitas yang tidak terpisahkan dari kehidupan manusia. Oleh karena itu, belajar memiliki sebuah arti penting bagi kehidupan manusia seperti yang diungkapkan oleh Syah yaitu sebagai key term (istilah kunci) yang paling vital dalam setiap usaha pendidikan, sehingga tanpa belajar sesungguhnya tidak pernah ada pendidikan. Hal ini membuktikan bahwa proses pendidikan yang ditempuh oleh siswa di sekolah tidak dapat dipisahkan dari aktivitas belajar. Meskipun demikian, bukan berarti bahwa belajar hanya terjadi ketika siswa berada di sekolah. ${ }^{3}$ Aktivitas belajar dapat dilakukan dimanapun mereka berada melalui berbagai proses kehidupan yang mereka lakukan. Seperti yang dilakukan Dryden, bahwa seseorang belajar $10 \%$ dari apa yang dibaca, 20\% dari apa yang didengar, 30\% dari apa yang dilihat, $50 \%$ dari apa yang dilihat dan didengar, 70\% dari apa yang ia katakan, 90\% dari apa yang ia katakan dan lakukan. Dengan adanya fasilitas belajar yang baik, diharapkan terjadi kompetisi yang sehat antar siswa untuk mendapatkan prestasi yang setinggitingginya. Dengan begitu, dari prestasi tersebut secara otomatis akan meningkatkan kualitas sumber daya manusia negeri ini. ${ }^{4}$

\section{Pentingnya Prestasi Belajar}

Menurut Mahmud, prestasi belajar mendapatkan perhatian khusus karena beberapa alasan, sebagai berikut: 5 
1. Kenyataan bahwa masa remaja itu merupakan saat persiapan untuk bekerja dikemudian hari menimbulkan masalah apa dan bagaimana persiapan itu dilakukan.

2. Para remaja mulai memahami sepenuhnya akan arti dan perbedaan prestasi belajar itu bagi keberhasilan-keberhasilan kini dan masa yang akan datang.

3. Pada masa remaja, anak-anak dihadapkan pada berbagai macam pilihan, baik sekolah maupun masa depan kerja.

4. Pada masa remaja timbulnya kemampuan-kemampuan untuk melihat akibat-akibat yang mungkin dihadapi di kemudian hari sebagai akibat dari pilihan-pilihannya mengenai sekolah dan pekerjaan.

5. Munculnya masalah prestasi itu berkaitan dengan perubahan-perubahan jasmaniah pada masa pubertas. Pada masa remajalah munculnya perbedaan prestasi belajar antara laki-laki dan perempuan.

\section{Indeks Prestasi}

Indeks prestasi, biasa disingkat IP, adalah salah satu alat ukur prestasi di bidang akademik/pendidikan. Meskipun bernama "indeks", IP sebenarnya bukanlah indeks dalam pengertian sebenarnya, melainkan semacam rerata terboboti. ${ }^{6}$

Dari tinjauan di atas, Allah swt. berfiman dalam QS al-Alaq/96: 1-5.

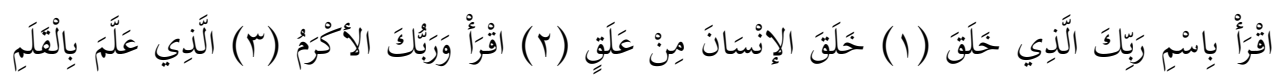

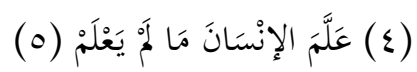

(1) bacalah dengan (menyebut) nama Tuhanmu yang Menciptakan, (2) Dia telah menciptakan manusia dari segumpal darah. (3) Bacalah, dan Tuhanmulah yang Maha Pemurah, (4) yang mengajar (manusia) dengan perantaran kalam, (5) Dia mengajar kepada manusia apa yang tidak diketahuinya".7

Dengan ayat ini terbuktilah tentang tingginya nilai membaca, menulis dan berilmu pengetahuan. Andai kata tidak karena kalam niscaya banyak ilmu pengetahuan yang tidak terpelihara dengan baik, banyak penelitian yang tidak tercatat dan banyak ajaran agama hilang, pengetahuan orang dahulu kala tidak dapat dikenal oleh orangorang sekarang baik ilmu, seni, dan ciptaan-ciptaan mereka. Demikian pula tanpa pena tidak dapat diketahui sejarah orang-orang yang berbuat baik atau yang berbuat jahat dan tidak ada pula ilmu pengetahuan yang menjadi pelita bagi orang-orang yang datang sesudah mereka. Lagi pula ayat ini sebagai bukti bahwa manusia yang dijadikan dari benda mati yang tidak berbentuk dan tidak berupa dapat dijadikan Allah menjadi manusia yang sangat berguna dengan mengajarinya pandai menulis, berbicara, dan mengetahui semua macam ilmu yang tidak pernah diketahuinya. Maksudnya: Allah swt. mengajar manusia dengan perantaraan tulis baca. ${ }^{8}$

\section{Sosial Media}

Sosial media adalah "sebuah kelompok aplikasi berbasis internet yang membangun di atas dasar ideologi dan teknologi Web 2.0, dan yang memungkinkan penciptaan dan pertukaran user-generated content". ${ }^{9}$ 


\section{Penggunaan Sosial Media}

Penggunaan internet dapat diartikan sebagai pemanfaatan jaringan komunikasi global dalam dunia maya untuk mencapai tujuan tertentu. Penggunaan internet untuk keperluan pendidikan yang semakin meluas terutama di negara-negara maju, merupakan fakta yang menunjukkan bahwa dengan adanya internet maka proses pembelajaran menjadi lebih efektif. Sebagai media yang diharapkan akan menjadi bagian dari proses pembelajaran, internet harus mampu memberikan dukungan bagi terselenggaranya proses komunikasi interaktif antara pendidik dan mahasiswa. Kegiatan komunikasi tersebut dilakukan oleh pendidik untuk mengajak dan membantu mahasiswa memperoleh materi yang dibutuhkan dalam mengerjakan tugas. ${ }^{10}$

\section{Situs Sosial Media (Facebook atau Twitter)}

\section{Facebook}

Menurut Wati, facebook merupakan jejaring sosial (social network) yang bisa dimanfaatkan oleh para pengguna untuk saling mengenal dan berkomunikasi dalam berbagai keperluan dan juga bersifat rekreasi. Facebook adalah situs website jejaring sosial yang diluncurkan pada 4 Februari 2004 dan didirikan oleh Mark Zuckerberg, seorang lulusan Harvard dan mantan murid Ardsley High School.11

\section{Twitter}

Menurut Wikipedia, twitter adalah layanan jejaring sosial dan mikroblog yang memungkinkan penggunanya untuk mengirim dan membaca pesan berbasis teks hingga 140 karakter, yang dikenal dengan sebutan kicauan (tweet). Twitter didirikan pada bulan Maret 2006 oleh Jack Dorsey, dan situs jejaring sosialnya diluncurkan pada bulan Juli. Sejak diluncurkan, twitter telah menjadi salah satu dari sepuluh situs yang paling sering dikunjungi di internet, dan dijuluki dengan "pesan singkat dari internet". ${ }^{12}$

\section{Dampak Positif dan Negatif Sosial Media}

Menurut Arfianingrum, ada beberapa dampak positif dan negatif yang dihasilkan sosial media, sebagai berikut: ${ }^{13}$

\section{Dampak Positif Sosial Media}

a. Sebagai media penyebaran informasi. Informasi yang up to date sangat mudah menyebar melalui situs jejaring sosial. Hanya dalam tempo beberapa menit setelah kejadian, seseorang telah bisa menikmati informasi tersebut.

b. Sebagai sarana untuk mengembangkan keterampilan dan sosial. Mengasah keterampilan teknis dan sosial merupakan kebutuhan yang wajib dipenuhi agar bisa bertahan hidup dan berada dalam neraca persaingan di era modern seperti sekarang ini.

c. Memperluas jaringan pertemanan. Dengan menggunakan jejaring sosial, seseorang bisa berkomunikasi dengan siapa saja, bahkan dengan orang yang belum 
dikenal sekalipun dari berbagai penjuru dunia. Kelebihan ini bisa dimanfaatkan untuk menambah wawasan, bertukar pikiran, saling mengenal budaya dan ciri khas daerah masing-masing.

2. Dampak Negatif Sosial Media

a. Kejahatan dunia maya (cyber crime). Seiring berkembangnya teknologi, berkembang pula kejahatan. Di dunia internet, kejahatan dikenal dengan nama cyber crime.

b. Melemahkan dan menurunkan sensitivitas. Penurunan sensitivitas yang dimaksud di sini adalah menurunnya tingkat simpati dan empati seseorang terhadap dunia nyata. Merenggangkan dan mengabaikan sesuatu yang terjadi di sekitarnya dan lebih memilih untuk memperhatikan sesuatu yang terjadi di dunia maya.

c. Berkurangnya waktu belajar siswa/pengguna sehingga menjadi kurang bersosialisasi. Hal ini sudah jelas, karena dengan mengakses internet dan membuka situs jejaring sosial mahasiswa akan lupa waktu, sehingga yang dikerjakannya hanyalah itu-itu saja.

d. Tingkat kriminalitas yang meningkat, seperti kasus penculikan, penipuan, pornografi, dan lain-lain.

e. Kementerian Komunikasi dan Informatika (Kemenkominfo) akan melakukan penutupan situs radikal di Indonesia. Penutupan dilakukan setelah melalui pertimbangan dan masukan dari Badan Nasional Penanggulangan Teroris (BNPT) RI.

\section{METODE PENELITIAN}

\section{Jenis Penelitian}

Penelitian ini dirancang dalam bentuk penelitian deskriptif. Untuk mendeskripsikan setiap variabel dan mencari korelasi serta pengaruh-pengaruh variabel bebas terhadap variabel tidak bebas, desain penelitiannya harus disesuaikan. Desain penelitian yang akan digunakan adalah desain kausal yang bertujuan untuk melihat pengaruh variabel bebas terhadap variabel terikat. Pendekatan penelitian yang digunakan adalah penelitian kuantitatif.

\section{Populasi dan Sampel}

\section{Populasi}

Populasi dalam penelitian ini adalah seluruh mahasiswa regular yang aktif di semester II, IV, dan VI S1 Keperawatan Fakultas Ilmu Kesehatan UIN Alauddin Makassar. Jumlah total mahasiswa regular S1 Keperawatan Fakultas Ilmu Kesehatan UIN adalah 235 orang dengan perincian semester II (63 mahasiswa), semester IV (94 mahasiswa) dan semester VI (78 mahasiswa).

\section{Sampel}

Teknik pengambilan sampel dalam penelitian ini menggunakan "simple random sampling", yaitu dengan mengambil secara acak anggota populasi menjadi sampel. 
Jumlah responden dalam penelitian ini sebanyak 235 mahasiswa. Dari rumus didapatkan sampel 148 dibulatkan menjadi 150, maka dapat disimpulkan sampelnya terdiri 150 mahasiswa.

\section{Teknik Pengolahan dan Analisis Data}

\section{Teknik Pengolahan Data}

Pengolahan data menurut Hasan meliputi kegiatan:14
a. Editing
b. Coding (Pengkodean)
c. Tabulasi

\section{Analisis Data}

Penelitian ini menggunakan teknik analisis data sebagai berikut:
a. Univariat
b. Bivariat

\section{HASIL PENELITIAN}

Jumlah Mahasiswa Semester II, IV, dan VI Jurusan Keperawatan FIK Universitas Islam Negeri (UIN) Alauddin Makassar yang Menggunakan Internet secara Aktif dan Karakteristik

Karakteristik mahasiswa semester II, IV, dan VI S1 Keperawatan FIKES UIN Alauddin Makassar yang menggunakan internet secara aktif dan karakteristik dapat digambarkan dalam Tabel 1

\section{Tabel 1}

Karakteristik Mahasiswa Semester II, IV,dan VI Jurusan Keperawatan FIK Universitas Islam Negeri (UIN) Alauddin Makassar yang Menggunakan Internet Secara Aktif dan Karakteristik

\begin{tabular}{|c|c|c|c|c|c|}
\hline No & \multicolumn{3}{|l|}{ Karakteristik } & $\bar{n}$ & $\%$ \\
\hline \multirow[t]{3}{*}{1} & Umur & & & & \\
\hline & - $19-21$ Tahun & & & 85 & 56,7 \\
\hline & - $22-24$ Tahun & & & 65 & 43,3 \\
\hline \multirow[t]{3}{*}{2} & Jenis Kelamin & & & & \\
\hline & - Laki-Laki & & & 35 & 23,3 \\
\hline & - Perempuan & & & 115 & 76,7 \\
\hline \multirow[t]{5}{*}{3} & Mahasiswa/i Pengguna Aktif & \multirow{2}{*}{\multicolumn{2}{|c|}{ Aktif }} & & \\
\hline & & & & \multicolumn{2}{|c|}{ Tidak Aktif } \\
\hline & - Semester II & & 20 & 16 & 29,1 \\
\hline & - Semester IV & 33 & 34,7 & 18 & 32,7 \\
\hline & - Semester VI & 43 & 45,3 & 21 & 38,2 \\
\hline \multirow[t]{3}{*}{4} & Kapan Menggunakan Sosial Media & an 1 & itter) & & \\
\hline & $-\quad 2007-2010$ & & & 127 & 82 \\
\hline & $-\quad 2011-2013$ & & & 23 & 18 \\
\hline
\end{tabular}




\begin{tabular}{|c|c|c|c|}
\hline \multirow[t]{4}{*}{5} & Manfaat Sosial Media & & \\
\hline & - Informasi umum & 100 & 66,7 \\
\hline & - Keperluan belajar & 89 & 59.3 \\
\hline & - Isi waktu luang & 23 & 15,3 \\
\hline \multirow[t]{4}{*}{6} & Kelebihan Sosial Media & & \\
\hline & - Cepat dapat informasi & 97 & 64,7 \\
\hline & - Menambah ilmu pengetahuan & 73 & 48,7 \\
\hline & - Dapat banyak teman & 70 & 46,7 \\
\hline \multirow[t]{5}{*}{7} & Lama Mengakses Sosial Media & & \\
\hline & $-<3$ jam & 101 & 67,3 \\
\hline & $-3-6$ jam & 36 & 24 \\
\hline & $-6-12$ jam & 6 & 4 \\
\hline & $-\quad>12 \mathrm{jam}$ & 7 & 4,7 \\
\hline \multirow[t]{5}{*}{8} & Lama Aktivitas Belajar & & \\
\hline & $-<3$ jam & 82 & 54,7 \\
\hline & $-3-6$ jam & 52 & 34,7 \\
\hline & $-6-12$ jam & 14 & 9,3 \\
\hline & $-\quad>12$ jam & 2 & 1,3 \\
\hline \multirow[t]{4}{*}{9} & Akun Sosial Media (Facebook dan Twitter) & & \\
\hline & - Facebook & 56 & 37,3 \\
\hline & - Twitter & 2 & 1,3 \\
\hline & - Facebook dan Twitter & 92 & 61,4 \\
\hline
\end{tabular}

Jumlah mahasiswa yang dijadikan sebagai responden dalam penelitian ini berjumlah 150 orang. Sampel representatif dari 150 responden tersebut sebanyak 95 mahasiswa/i (63,3\%), yaitu yang menggunakan internet secara aktif dan waktu mengakses mahasiswa/i rata-rata kurang dari 3 jam sebanyak 101 orang (67,3\%). Pengguna internet dikatakan aktif apabila waktu rata-rata yang digunakan untuk mengakses internet 1-2 jam per hari. ${ }^{15}$ Jadi, 55 responden $(36,7 \%)$ merupakan pengguna internet yang tidak aktif karena mereka menggunakan internet $<1-2$ jam dalam sehari. Sebagaimana firman Allah swt. dalam surah Al-A'Raaf/7:31

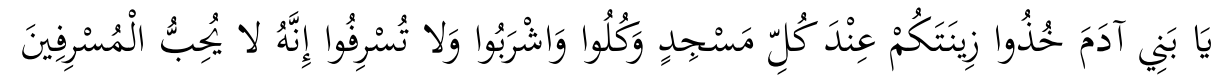

Hai anak Adam, pakailah pakaianmu yang indah di Setiap (memasuki) mesjid (534), Makan dan minumlah, dan janganlah berlebih-lebihan (535). Sesungguhnya Allah tidak menyukai orang-orang yang berlebih-lebihan. ${ }^{16}$

Al-Musrifin berasal dari kata asrafa-yusrifu yang dapat diartikan dengan melampaui batas atau berlebih-lebihan. Seseorang yang mengerjakan sesuatu atau menggunakan sesuatu dengan sikap tidak wajar dan melebihi batas yang normal, dapat dikatakan bahwa ia telah bersikap israf atau melampaui batas kewajaran. ${ }^{17}$ Dapat disimpulkan, bahwa dalam melakukan/memakai sesuatu harus dilakukan dengan sewajarnya. 


\section{Perbandingan Hasil Belajar Mahasiswa Semester II-III, IV-V, dan VI-VII Jurusan Keperawatan FIK Universitas Islam Negeri (UIN) Alauddin Makassar}

Perbandingan hasil belajar mahasiswa semester II-III, IV-V, dan VI-VII Jurusan Keperawatan FIK Universitas Islam Negeri (UIN) Alauddin Makassar dapat digambarkan di tabel 2

\section{Tabel 2}

Perbandingan Hasil Belajar Mahasiswa Semester II-III, IV-V, dan VI-VII Jurusan Keperawatan FIK Universitas Islam Negeri (UIN) Alauddin Makassar

\begin{tabular}{llcccccc}
\hline No & \multicolumn{1}{c}{ Tahun } & \multicolumn{2}{c}{ Cum Laude } & \multicolumn{2}{c}{ Sangat Memuaskan } & \multicolumn{2}{c}{ Memuaskan } \\
& & $\mathrm{n}$ & $\%$ & $\mathrm{n}$ & $\%$ & $\mathrm{n}$ & $\%$ \\
$\mathbf{1}$ & 2011 & & & & & & \\
& Semester VI & 1 & 1,6 & 57 & 89 & 6 & 9,4 \\
& Semester VII & 31 & 48,4 & 33 & 51,6 & 0 & 0 \\
$\mathbf{2}$ & $\begin{array}{l}2012 \\
\end{array}$ & & & & & & \\
& Semester IV & 1 & 2,8 & 24 & 68,6 & 10 & 28,6 \\
& Semester V & 0 & 0 & 29 & 82,9 & 6 & 17,1 \\
3 & 2013 & & & & & & \\
& Semester II & 1 & 2 & 43 & 84,3 & 7 & 13,7 \\
& Semester III & 7 & 13,7 & 40 & 78,5 & 4 & 7,8 \\
\hline
\end{tabular}

Hasil belajar merupakan kemampuan yang dimiliki mahasiswa setelah ia menerima pengalaman belajar. ${ }^{18}$ Prestasi dalam belajar merupakan keinginan setiap mahasiswa. Prestasi yang baik akan didapat dengan proses belajar yang baik juga. Belajar merupakan proses dari sesuatu yang belum bisa menjadi bisa, dari perilaku lama ke perilaku yang baru, dari pemahaman lama ke pemahaman baru. Hasil belajar semester genap mahasiswa semester II, IV, dan VI S1 Keperawawatan FIK Universitas Islam Negeri (UIN) Alauddin Makassar terbanyak dalam kategori sangat memuaskan yaitu dengan indeks prestasi 2,75-3,50 berjumlah 124 mahasiswa (82,7\%) sedangkan kategori memuaskan (IP 2,00-2,74) berjumlah 23 orang (15,3\%) dan kategori Cum Laude (IP 3,51-4,00) berjumlah 3 orang $(2 \%)$.

Sebagaimana sabda Rasulullah saw.

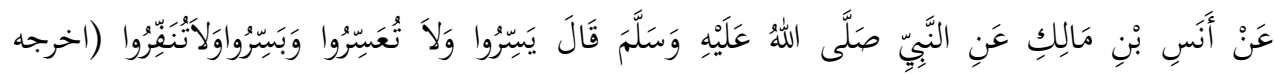

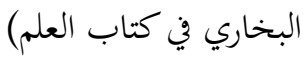

Dari Anas bin Malik dari Nabi saw "mudahkanlah dan jangan kamu persulit. Gembirakanlah dan jangan kamu membuat lari" (HR. Abu Abdillah Muhammad bin Ismail al-Bukhori al-Ju'fi) (Terjemah Sahih Bukhori, hlm 89). ${ }^{19}$

Hadis di atas menjelaskan bahwa proses pembelajaran harus dibuat dengan mudah sekaligus menyenangkan agar peserta didik tidak tertekan secara psikologis dan tidak merasa bosan terhadap suasana di kelas, serta apa yang diajarkan oleh gurunya. Dan suatu pembelajaran juga harus menggunakan metode yang tepat dise- 
suaikan dengan situasi dan kondisi, terutama dengan mempertimbangkan keadaan orang yang akan belajar. ${ }^{20}$

\section{Pengaruh Sosial Media (facebook dan twitter) terhadap Perubahan Indeks Prestasi Mahasiswa}

Pengaruh keaktifan sosial media (Facebook dan Twitter) dengan indeks prestasi mahasiswa dapat digambarkan di tabel 3.

Tabel 3

Pengaruh Keaktifan Sosial Media (Facebook dan Twitter) dengan Indeks Prestasi Mahasiswa

\begin{tabular}{clccc}
\hline No & Perubahan Indek Prestasi & Aktif & Tidak Aktif & P value \\
\hline $\mathbf{1}$ & Meningkat & 71 & 43 & \\
$\mathbf{2}$ & Tetap & 8 & 2 & 0,017 \\
$\mathbf{3}$ & Menurun & 16 & 10 & \\
\multicolumn{2}{c}{ Jumlah } & 95 & 55 & \\
\hline
\end{tabular}

Penelitian ini memiliki nilai sigfikansi (2 tailed) sebesar 0,017 dan nilai $\mathrm{p}(<0,05)$, menunjukkan terdapat hubungan yang signifikan antara "sosial media (facebook dan twitter)" dengan "indeks prestasi mahasiswa" sedangkan nilai koefisien korelasi sebesar 0,19 menunjukkan ada hubungan positif yaitu 19\%. Hal tersebut berarti penggunaan sosial media memiliki pengaruh positif yang kecil terhadap peningkatan indeks prestasi mahasiswa mahasiswa semester gasal S1 Keperawatan FIK Universitas Islam Negeri (UIN) Alauddin Makassar. Dengan begitu, dapat disimpulkan bahwa penggunaan sosial media memiliki pengaruh signifikan terhadap peningkatan indeks prestasi mahasiswa semester gasal S1 Keperawatan FIK Universitas Islam Negri (UIN) Alauddin Makassar.

Berdasarkan penelitian Sarita, terungkap bahwa bahwa terdapat beberapa faktor yang mempengaruhi perubahan indeks prestasi mahasiswa. ${ }^{21}$ Faktor tersebut menjadi variabel perancu dalam penelitian ini, sehingga terdapat pengaruh yang signifikan antara sosial media (facebook dan twitter) terhadap indeks prestasi mahasiswa semester III, V, dan VII S1 Keperawatan FIK Universitas Islam Negeri (UIN) Alauddin Makassar.

\section{SIMPULAN}

Mahasiswa(i) dalam hal penggunaan sosial media berarti memiliki pengaruh positif terhadap peningkatan indeks prestasi mahasiswa mahasiswa semester gasal S1 Keperawatan FIK Universitas Islam Negri (UIN) Alauddin Makassar. Dari dampak positif sosial media yang sebagai media penyebar informasi dan juga dimanfaatkan untuk menambah wawasan, bertukar pikiran, saling mengenal budaya dan ciri khas daerah masing-masing. 


\section{CATATAN AKHIR:}

1. Abuddin Nata, Tokoh-tokoh Pembaruan Pendidikan Islam di Indonesia, Jakarta: PT RajaGrafindo Persada, 2005, h. vi.

2. Abuddin Nata, Tokoh-tokoh Pembaruan Pendidikan Islam di Indonesia, h. 392.

1. https://etikajejaringsosial.wordpress.com/about/pembahasan/sejarah-dan perkembangan-jejaring-sosial/. "Sejarah dan Perkembangan Jejaring Sosial", EtikaJejaringSosial.Wordpress.com, 2012 (diakses 3 Januari 2015).

2. Fitri. Pengarih facebook terhadap nilai akademik mahasiswa STMIK Amikom Yogyakarta. 2013.

3. Syah. Psikologi Belajar. (Jakarta: PT. Raja Grafindo Persada. 2009), h 59.

4. Dryden, Gordon and Jeanette Vos. Revolusi Cara Belajar. (Penyunting Akhmat Baiquni. Bandung: KAIFA. 2001), h 100.

5. Mahmud. Psikologi Pendidikan. (Cet I. Jakarta: Pustaka Setia. 2010).

6. Wijaya. "Mengenal Indeks Prestasi", KutuKuliah.Blogspot.com, Mei 2013. (diakses 5 Januari 2015).

7. Departemen Agama RI. Al-Qur'an dan Terjemahan. (Cet 1. 1979), h 1079.

8. Departemen Agama RI. Al-Qur'an dan Terjemahan. (Cet 1. 1979), h 1079.

9. Kaplan. "Users of the world, unite! The challenges and opportunities of Social Media". (Business Horizons. 2010).

10. Pardosi. Merancang Website Gratis Dengan Microsoft Frontpage. (Surabaya: Indah. 2002).

11. Wati. 5 Jam Menjadi Terkenal Lewat Facebook. (Bandung: CV. Yrama Widya. 2009).

12. Wikipedia. "Twitter", Wikipedia.com. (diakses 9 Januari 2015).

13. Arfianingrum. Pengaruh Jejaring Sosial Terhadap Aktivitas Belajar Mahasiswa Fakultas Komputer Institut Bisnis Nusantara. 2013.

14. Hasan. Analisis Data Penelitian dengan Statistik. (Jakarta: Bumi Aksara. 2006).

15. Yani. Voip Nelpon Murah Pake Internet. (Jakarta: Kawan Pustaka. 2009).

16. Departemen Agama RI. Al-Qur'an dan Terjemahan. (Cet 1. 1979), h 225.

17. Al-Jalalain. Tafsir al-Jalalain, dicetak dalam Tasir al-Shawy, Dar Ihya al-Kutub al-Arabiyah. (Indonesia. Juz. II. 1988), h 194.

18. Goeroendeso. Computer sebagai Media pembelajaran. 2009 (diakses 22 Februari 2015).

19. Toha. Terjemah Sahih Bukhori. (Jakarta: Pustaka Panjimas. 1986), h 89.

20. Ismail. Strategi Pembelajaran Agama Islam Berbaisis PIKEM. (Semarang: Rasail Media Group. 2008), h 13.

21. Sarita. Pola Penggunaan dan Dampak Internet Di kalangan Mahasiswa Institut Pertanian Bogor. 2008 (diakses 21 Februari 2015).

\section{DAFTAR PUSTAKA}

Arfianingrum, Resti dan Sri Mulyono. Pengaruh Jejaring Sosial terhadap Aktivitas Belajar Mahasiswa Fakultas Komputer Institut Bisnis Nusantara. 2013.

Departemen Agama RI. Al-Qur'an dan Terjemahan. Cet 1. 1979.

Dryden, Gordon and Jeanette Vos. Revolusi Cara Belajar. Penyunting Akhmat Baiquni. Bandung: KAIFA. 1999.

Fitri, Sulidar dan Hartatik. Pengaruh Facebook terhadap Nilai Akademik Mahasiswa STMIK Amikom Yogyakarta. 2013.

Goeroendeso. Computer sebagai Media Pembelajaran. 2009. http://goeroendeso.files.wordpress.com/2009/03/7-media-komputer.pdf/(Diakses 22 Februari 2015).

Hasan, Iqbal. Analisis Data Penelitian dengan Statistik. Jakarta: Bumi Aksara. 2006. 
https://etikajejaringsosial.wordpress.com/about/pembahasan/sejarah-dan perkembanganjejaring-sosial/ (Diakses 3 Januari 2015). "Sejarah dan Perkembangan Jejaring Sosial", Etika JejaringSosial.Wordpress.com, 2012.

Ismail SM. Strategi Pembelajaran Agama Islam Berbaisis PIKEM. Semarang: Rasail Media Group. 2008.

Al-Jalalain. Tafsir al-Jalalain, dicetak dalam Tasir al-Shawy, Dar Ihya al-Kutub al-Arabiyah. Indonesia. Juz. II. 1988.

Kaplan, Andreas M dab Michael Haenlein. "Users of the World, Unite! The Challenges and Opportunities of Social Media". Business Horizons. 2010.

Luthfi, Ahmad (okezone). "Indonesia Pengguna Facebook Keempat Terbesar di Dunia". Situs Resmi Okezone. http://techno.okezone.com/read/2014/ 09/22/55/1042737/indonesia-pengguna-facebook-terbesar-di-dunia/large (Diakses 31 Desember 2014).

Mahmud. Psikologi Pendidikan. Cet I. Jakarta: Pustaka Setia. 2010.

Pardosi, Mico. Merancang Website Gratis dengan Microsoft Frontpage. Surabaya: Indah. 2002.

Sarita, Sushane. Pola Penggunaan dan Dampak Internet Dikalangan Mahasiswa Institut Pertanian Bogor. 2008. http://repository.ipb.ac.id/bitstream/handle/123456789/2885/A08ssa.pdf? sequence $=4$ (Diakses 21 Februari 2015).

Syah, Muhibbin. Psikologi Belajar. Jakarta : PT. Raja Grafindo Persada. 2009.

Toha, Ahmadi. Terjemah Sahih Bukhori. Jakarta: Pustaka Panjimas. 1986.

Wati, Mardiana dan A.R. Rizky. 5 Jam Menjadi Terkenal Lewat Facebook. Bandung: CV. Yrama Widya. 2009.

Wijaya, Wira, “Twitter”, Wikipedia.com. http://id.wikipedia.org/wiki/Twitter (Diakses 9 Januari 2015).

Wijaya, Wira. "Mengenal Indeks Prestasi", KutuKuliah.Blogspot.com, Mei 2013. http://kutukuliah.blogspot.com/2013/05/mengenal-indeks-prestasi- adalah-.html (Diakses 5 Januari 2015).

Yani, Ahmad. Voip Nelpon Murah Pake Internet. Jakarta: Kawan Pustaka. 2009. 